\title{
Factors correlating with shorter survival after treatment: aiding oncologists to choose who (not) to receive palliative systemic therapy
}

\author{
Pui Ying Patty $\mathrm{Ho}^{1}$, Ho Fun Victor Lee ${ }^{2}$ \\ ${ }^{1}$ Department of Clinical Oncology, Queen Mary Hospital, Hong Kong, China; ${ }^{2}$ Department of Clinical Oncology, University of Hong Kong, Hong \\ Kong, China \\ Contributions: (I) Conception and design: All authors; (II) Administrative support: None; (III) Provision of study materials or patients: PY Ho; (IV) \\ Collection and assembly of data: PY Ho; (V) Data analysis and interpretation: All authors; (VI) Manuscript writing: All authors; (VII) Final approval \\ of manuscript: All authors. \\ Correspondence to: Pui Ying Patty Ho. 1/F Professorial Block, Queen Mary Hospital, Pokfulam, Hong Kong, China. Email: pattypyho@gmail.com.
}

Background A rising number of metastatic cancer patients are receiving palliative systemic therapy close to end of life. Patients started on such treatment are typically judged by oncologists to have at least 12 weeks survival, however, accurate survival prediction on individual patients is difficult. Systemic therapy started too late may not benefit patient, but rather, adversely affect patient's quality of life and may even shorten survival due to treatment-related side effects. Our objective is to identify factors correlating with a shorter ( $\leq 6$ weeks) non-malignancy related survival in metastatic cancer patients receiving palliative systemic therapy, so as to aid oncologist in the decision-making of starting treatment or not.

Methods: A review of deceased metastatic cancer patients treated with palliative systemic therapy and died between January 2013 and December 2014 was carried out. They were subcategorized into dying within or after 6 weeks since starting their last line of palliative systemic therapy, and also by cause of death (malignancy-related or non-malignancy related causes). Demographics, clinical characteristics, and type of systemic therapy used were assessed using non-parametric Mann Whitney-U tests for continuous variables and $\chi^{2}$ tests for categorical variables. Univariable analyses were carried out to determine associations of different variables with non-malignancy related death that happened within 6 weeks of starting their last line of palliative systemic therapy. Multivariable analyses were carried out with significant factors in univariable analyses to determine their independent effect.

Results: Seven hundred and fifty-four patients were analyzed. Mean age was 63.6 (range, 21-102); female $48.7 \%$. Older age $(75$ years $)(P=0.007)$ and active liver metastasis $(\mathrm{P}=0.042)$ were significant predictors for early ( $\leq 6$ weeks) non-malignancy related death in multivariable analysis. They have 2.012 and 1.115 times higher chance respectively to die of non-malignant causes within 6 weeks since the start of their last line of palliative systemic treatment.

Conclusions: Oncologists should exercise extra caution when encountering elderly patients with active liver metastasis, especially with regard to the issue of starting palliative systemic therapy.

Keywords: Early death; elderly; liver metastasis; metastatic cancer patients; palliative systemic therapy

Submitted Apr 13, 2019. Accepted for publication Aug 27, 2019.

doi: 10.21037/apm.2019.09.06

View this article at: http://dx.doi.org/10.21037/apm.2019.09.06 


\section{Introduction}

Survival outcomes for malignancies have greatly improved in the past 15 years after the advent of new generations of chemotherapy, targeted therapy and more recently, immunotherapy. Indeed, the discoveries of driving mutations and growth factor pathway leading to tumour proliferation and inhibition of apoptosis have led to the design of targeted drugs. This has greatly prolonged the survival, and may be more importantly, a better quality of life (QOL) for patients, sparing them from the devastating and profound side effects associated with the older generations of chemotherapy. International multi-center phase III randomized-controlled trials have clearly demonstrated that the use of new generations of chemotherapy, targeted therapy, and hormonal therapy either alone or in combination has produced excellent response rate and significant improvement of progression-free survival and probably overall survival.

Nevertheless, even the best targeted drug could only produce an objective response rate of up to $80 \%$ and a median progression-free survival of around 18 months (Table 1). In other words, about $20 \%$ of patients develop primary disease progression even though their tumors harbor the sensitizing and druggable mutations; while the remaining $80 \%$ of patients who are initially responsive to these therapies will develop disease progression afterwards, leading to treatment cessation. Eventually these patients shall have to switch to second and then subsequent lines of treatment, with an aim to further prolong the survival. Unfortunately, the efficacies of these second or subsequent lines of treatment are becoming worse when patients carry on with the therapy, primarily because of emergence of acquired drug resistance due to tumour clonal selection. Patients' performance status will also gradually deteriorate secondary to disease progression, accompanied by the more protracted side effects carried forward by the previous treatment. In addition, the side effects of these second or subsequent lines of therapy are usually more detrimental to their physical functions and QOL, leading to more treatment-related side effects or even life-threatening complications, resulting in premature mortality.

Despite the above, with emerging new weapons on hand, there still has been a trend of prolonging treatment duration for metastatic cancer patients in the past 2 decades, resulting in a significant proportion of patients still receiving active systemic treatment near the end of their life. A Swedish population-based cohort study (52) found that up to one- fourth of Swedish terminal solid cancer patients still received chemotherapy during their last month of life. Two large studies based on Medicare claims, encompassing around 8,000 patients each, found that $15 \%$ of terminal cancer patients were receiving chemotherapy in their last week of life $(53,54)$. Two institution-based studies done in Italy showed that $23 \%$ and $15 \%$ of advanced cancer patients were receiving chemotherapy in their last month of life $(55,56)$. A Korean report even found up to $50 \%$ of terminal cancer patients received chemotherapy in the last 2 months of life (57).

It is now well recognized that appropriately timed cessation of anti-tumour systemic treatment is a core issue in the holistic management of cancer patients. Chemotherapy cessation in the last 2 weeks of life is adopted by American Society of Clinical Oncology (ASCO) as one of the measures for improving clinical practice in Quality Oncology Practice Initiative $\left(\mathrm{QOPI}^{\mathrm{TM}}\right)$. ASCO guidelines also specifically recommend against the use of chemotherapy in patients with solid tumors who have not benefitted from previous lines of treatment, and who have an Eastern Cooperative Oncology Group (ECOG) performance score (PS) of more than 3 (58). Naturally, one would deduce and believe that patients with better PS are more likely than those with worse PS to derive clinical benefit from toxic systemic therapies. Thus, 'fitter' patients are generally more likely to receive a longer duration of treatment, or more lines of palliative systemic therapy. However, in 2015, Prigerson et al. have shown in a prospective cohort study, that palliative chemotherapy given to terminal cancer patients not only did not improve the QOL of those with a poor PS, but even worsened the QOL of those patients who started off with a better PS (59).

This made us wonder, if even those with still a good ECOG PS can be harmed by systemic treatment started too late, there must be a certain proportion of patients who actually suffered from earlier death directly or indirectly related to the treatment we have provided. Individual patient's survival is known to be difficult to predict, especially regarding metastatic cancer patients approaching end of life. Systematic review found clinicians are only around $25 \%$ accurate and frequently overestimate (60). How can we better identify at risk patients beforehand and avoid starting systemic therapy in them, with a hope to preserve survival and promote their QOL near death? So far there has been very little information on the factors that can accurately correlate with non-malignancy related survival in cancer patients on systemic treatment. The aim of this study is to identify any such factors. 
Table 1 List of multi-centre phase III randomized-controlled trials on new chemotherapeutic agents, targeted drugs and hormonal therapy as first-line treatment for common metastatic malignancies

\begin{tabular}{|c|c|c|c|c|c|c|}
\hline Study & Site & Study medication & $\begin{array}{l}\text { Number of } \\
\text { patients in study }\end{array}$ & $\begin{array}{l}\text { Response } \\
\text { rate, \% }\end{array}$ & $\begin{array}{l}\text { Median progression- } \\
\text { free survival (months) }\end{array}$ & $\begin{array}{l}\text { Median overall } \\
\text { survival (months) }\end{array}$ \\
\hline Mok $(1,2)$ & Lung & Gefitinib & 1,217 & 71.2 & Not reported & 21.6 \\
\hline Mitsudomi (4) & Lung & Gefitinib & 177 & 62.1 & 9.2 & Not reached \\
\hline Rosell (7) & Lung & Erlotinib & 174 & 63.6 & 9.7 & 19.3 \\
\hline Sequist (8) & Lung & Afatinib & 345 & 56.0 & 11.1 & Not reached \\
\hline Wu (9) & Lung & Afatinib & 364 & 66.9 & 11.0 & 22.1 \\
\hline Barlesi (13) & Lung & $\begin{array}{c}\text { Bevacizumab }+ \text { pemetrexed }+ \\
\text { cisplatin }\end{array}$ & 376 & 55.5 & 7.4 & Not reached \\
\hline Hurwitz (14) & Colorectal & $\begin{array}{c}\text { Bevacizumab + irinotecan + } \\
5-\mathrm{FU}+\text { leucovorin }\end{array}$ & 813 & 44.8 & 10.6 & 20.3 \\
\hline Van Cutsem (15) & Colorectal & Cetuximab + FOLFIRI & 599 & 46.9 & 8.9 & 19.9 \\
\hline Maughan(16) & Colorectal & $\begin{array}{c}\text { Cetuximab + capecitabine }+ \\
\text { oxaliplatin }\end{array}$ & 1,630 & 64.0 & 8.6 & 17.0 \\
\hline Tol (17) & Colorectal & $\begin{array}{l}\text { Cetuximab + bevacizumab + } \\
\text { capecitabine + oxaliplatin }\end{array}$ & 755 & 52.7 & 9.4 & 19.4 \\
\hline Valero (20) & Breast & $\begin{array}{l}\text { Trastuzumab + docetaxel + } \\
\text { carboplatin }\end{array}$ & 236 & 72.0 & 10.4 & 37.4 \\
\hline Baselga (21-23) & Breast & $\begin{array}{c}\text { Pertuzumab + trastuzumab + } \\
\text { docetaxel }\end{array}$ & 808 & 68.4 & 18.7 & 56.5 \\
\hline Baselga (24) & Breast & Exemestane + everolimus & 724 & 9.5 & 10.6 & Not reached \\
\hline Bang (25) & Stomach & $\begin{array}{l}\text { Trastuzumab + cisplatin } \\
+5-\mathrm{FU} / \text { capecitabine }\end{array}$ & 594 & 47.0 & 6.7 & 13.8 \\
\hline Von Hoff (26) & Pancreas & $\begin{array}{c}\text { Gemcitabine + albumin-bound } \\
\text { paclitaxel }\end{array}$ & 861 & 23.0 & 5.5 & 8.5 \\
\hline Conroy (27) & Pancreas & $\begin{array}{c}5-F U+\text { oxaliplatin + irinotecan } \\
\text { (FOLFIRINOX) }\end{array}$ & 342 & 31.6 & 6.4 & 11.1 \\
\hline Vermorken (28) & Head \& neck & Cetuximab + platinum + 5-FU & 442 & 36.0 & 5.6 & 10.1 \\
\hline Ryan (29) & Prostate & Abiraterone & 1,088 & 36.0 & 16.5 & Not reached \\
\hline
\end{tabular}

Table 1 (continued) 
Table 1 (continued)

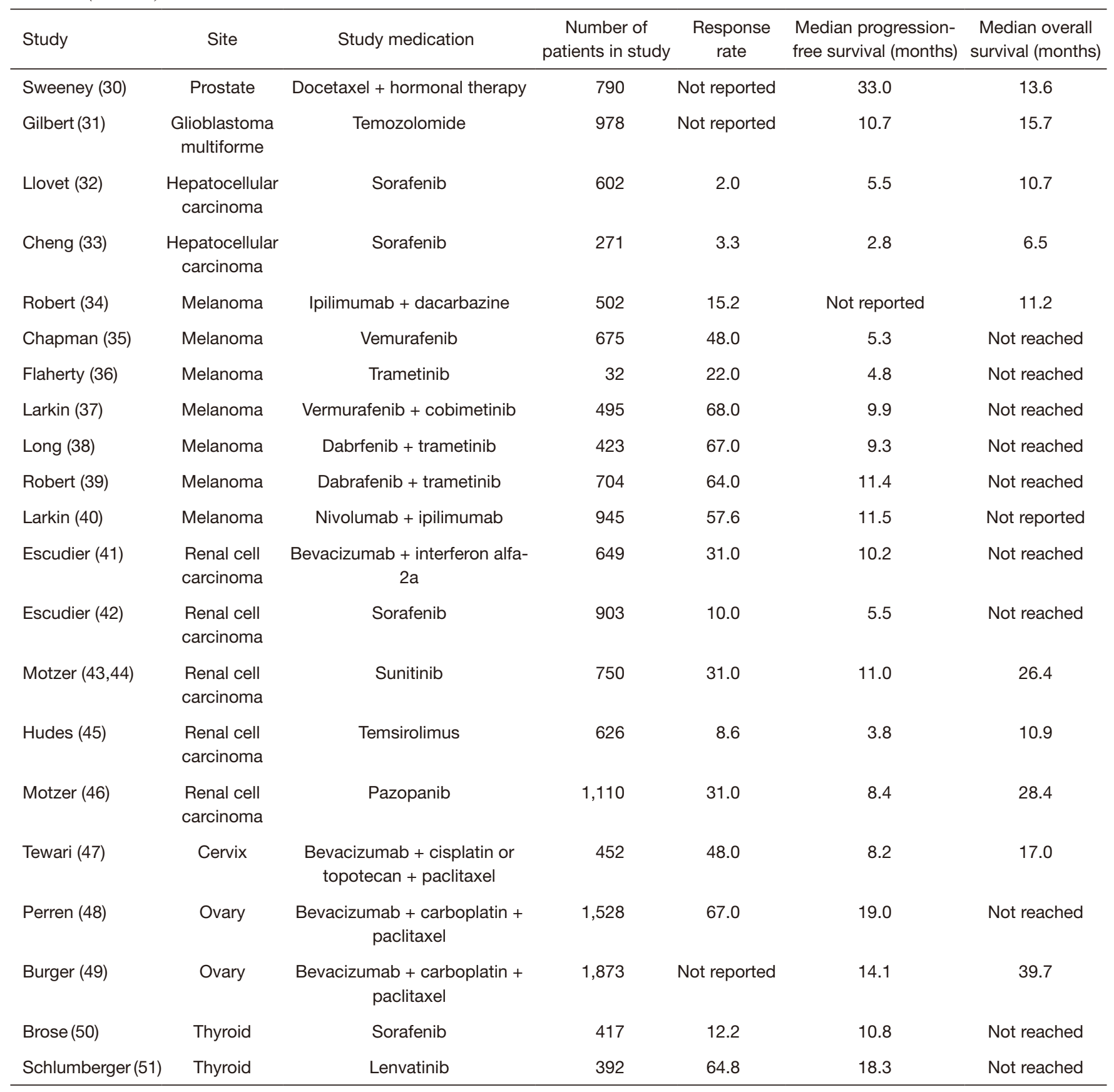

\section{Methods}

\section{Patients and methods}

All adult patients with metastatic malignant diseases (excluding hematological malignancies) who were managed in the Department of Clinical Oncology, Queen Mary
Hospital, Hong Kong, and subsequently passed away between $1^{\text {st }}$ January 2013 and $31^{\text {st }}$ December 2014 in public hospitals of the Hong Kong West Cluster (HKWC), Hospital Authority, Hong Kong were retrospectively reviewed. HKWC consists of mainly 3 hospitals, namely, Queen Mary Hospital (the affiliated hospital of the 
University of Hong Kong, with inpatient and outpatient clinical oncology service and palliative care services), Grantham Hospital and Tung Wah Hospital (both with inpatient and home-based palliative care services), along with other rehabilitation institutions.

Out of 1,393 patients, $754(54.1 \%)$ received at least one line of palliative systemic treatment, and they were further analyzed in this study. These patients were all anticipated by the treating oncologists to have a life expectancy of at least 12 weeks before they started the last line of palliative systemic treatment. Demographic data including age, sex, age at the time of metastasis, number of lines of prior palliative systemic treatment, type of their last line of palliative systemic treatment (chemotherapy, targeted therapy, chemotherapy plus targeted therapy, hormonal therapy), ECOG PS before start of last line of palliative systemic treatment, presence of active brain and liver metastases (excluding patients who had received radical resection or radical dose of stereotactic radiosurgery/radiation therapy), presence of active spinal cord compression, serum hematology and biochemistry taken within 1 week before the start of last line of palliative systemic treatment, start date of administration of last line of palliative systemic treatment, end date of administration of last line of palliative systemic treatment before death, date of death and cause of death were captured from the Clinical Management System (CMS) of the Hospital Authority of Hong Kong.

We sub-categorized eligible patients into those who passed away within 42 days (6 weeks) $(n=110)$ or after 42 days $(n=644)$ since the commencement of their last line of palliative systemic treatment, and also according to their cause of death, with an aim to identify any predictive factors for this early, non-disease related death in those who died within 42 days using subsequent statistical analysis.

We defined early non-malignancy related death as death within 42 days (6 weeks) after the start of last line of palliative systemic treatment, which is less than or equal to half of the anticipated life expectancy (12 weeks) in patients when they are judged eligible for recruitment into clinical trials for any study medication used in metastatic setting. Non-malignancy related death was defined as death due to reasons other than their malignancy, including treatmentrelated neutropenic fever/sepsis, non-neutropenic fever/ sepsis, and intercurrent diseases. Deaths secondary to sudden cardiopulmonary arrest of unknown cause were excluded from non-malignancy related death. If nonmalignancy related death takes place within 42 days since the start of last line of palliative systemic treatment, this suggests that the last line of palliative systemic treatment might not be offering any survival prolongation but rather may have contributed to survival shortening.

The primary study objective was to identify any factors correlating with non-malignancy specific survival (defined below) of the patient subgroup that died within 42 days since the start of the last line of palliative systemic treatment. Secondary objectives were non-malignancy specific survival of this subgroup, non-malignancy specific survival of the whole study population, and overall survival of the patient subgroups and the whole study population.

\section{Statistical analysis}

Comparison between demographic, clinical characteristics, use of chemotherapy/targeted therapy/hormonal therapy were assessed using non-parametric Mann Whitney-U tests for continuous variables and $\chi^{2}$ tests for categorical variables. Kaplan-Meier methods were used to estimate overall survival (calculated from the date of start of last line of palliative systemic treatment to the date of death of any cause) and non-malignancy specific survival (calculated from the date of start of last line of palliative systemic treatment to the date of death other than malignancy, excluding those who died of sudden cardiopulmonary arrest of unknown cause). Differences in overall survival and non-malignancy specific survival by different subgroups were assessed by logrank tests. Binary logistic regression with univariable and multivariable analyses were performed for the identification of risk factors for non-malignancy related death within 42 days since the last line of palliative systemic treatment. Only variables found significant in univariable analysis $(\mathrm{P}<0.1)$ were considered in the subsequent multivariable analysis. All statistical analyses were performed by Statistical Package for Social Sciences version 23 (Chicago, IL, USA). Statistical significance was defined as $\mathrm{P}<0.05$ (two-sided).

\section{Results}

\section{Baseline patient characteristics}

Table 2 showed the baseline patient characteristics before the start of last line of palliative systemic treatment. About one-third of all 754 patients suffered from lung cancer, followed by colorectal cancer, breast cancer, prostate cancer, hepatocellular carcinoma, etc. Rarer malignancies were grouped under the category "Others", including germ 
Table 2 Baseline patient characteristics before commencement of last line of palliative systemic treatment

\begin{tabular}{|c|c|}
\hline Parameters & $\mathrm{N}=754(\%)$ \\
\hline Mean age in years (range) & $63.6[21-102]$ \\
\hline Male/female & $387(51.3) / 367(48.7)$ \\
\hline \multicolumn{2}{|l|}{ ECOG PS } \\
\hline 0 & $4(0.5)$ \\
\hline 1 & $504(66.8)$ \\
\hline 2 & $203(26.9)$ \\
\hline 3 & $43(5.7)$ \\
\hline \multicolumn{2}{|l|}{ Cancer types } \\
\hline Lung & $247(32.8)$ \\
\hline Colorectal & $122(16.2)$ \\
\hline Breast & $92(12.2)$ \\
\hline Prostate & $49(6.5)$ \\
\hline Hepatocellular carcinoma & $40(5.3)$ \\
\hline Stomach & $39(5.2)$ \\
\hline Pancreas & $24(3.2)$ \\
\hline Biliary tract & $17(2.3)$ \\
\hline Nasopharyngeal carcinoma & $17(2.3)$ \\
\hline Oesophagus & $16(2.1)$ \\
\hline Head and neck & $14(1.9)$ \\
\hline Soft tissue sarcoma & $14(1.9)$ \\
\hline Renal cell carcinoma & $12(1.6)$ \\
\hline Ovary & $7(0.9)$ \\
\hline Uterus & $7(0.9)$ \\
\hline Glioblastoma multiforme & $4(0.5)$ \\
\hline Cervix & $3(0.4)$ \\
\hline Others & $30(4.0)$ \\
\hline Active brain metastasis & $73(9.7)$ \\
\hline Active spinal cord compression & $4(0.5)$ \\
\hline Active liver metastasis & $273(36.2)$ \\
\hline \multicolumn{2}{|c|}{ Number of prior lines of palliative systemic treatment (range) } \\
\hline 1 & $343(45.5)$ \\
\hline 2 & $181(24.0)$ \\
\hline 3 & $88(11.7)$ \\
\hline$\geq 4$ & $142(18.8)$ \\
\hline Median (range) & $2[1-13]$ \\
\hline
\end{tabular}

Table 2 (continued)
Table 2 (continued)

\begin{tabular}{|c|c|}
\hline Parameters & $\mathrm{N}=754(\%)$ \\
\hline \multicolumn{2}{|c|}{$\begin{array}{l}\text { Blood results immediately before last line of palliative systemic } \\
\text { treatment }\end{array}$} \\
\hline Median white cell count $\left(\times 10^{9} / \mathrm{L}\right)$ (range) & $7.19(1.70-84.61)$ \\
\hline $\begin{array}{l}\text { Median absolute neutrophil count } \\
\left(\times 10^{9} / L\right) \text { (range) }\end{array}$ & $5.21(0.56-79.97)$ \\
\hline Median haemoglobin (g/dL) (range) & $11.7(6.1-16.8)$ \\
\hline $\begin{array}{l}\text { Median albumin (calcium-adjusted) } \\
(\mathrm{g} / \mathrm{L}) \text { (range) }\end{array}$ & 38 [19-51] \\
\hline \multicolumn{2}{|c|}{ Types of last line of palliative systemic treatment } \\
\hline Chemotherapy & $371(49.2)$ \\
\hline Chemotherapy plus targeted therapy & $109(14.5)$ \\
\hline Targeted therapy & $197(26.1)$ \\
\hline Hormonal therapy & $77(10.2)$ \\
\hline \multicolumn{2}{|l|}{ Cause of death } \\
\hline Malignancy & $587(77.9)$ \\
\hline All non-malignancy related death & $159(21.1)$ \\
\hline Neutropenic fever/sepsis & $8(1.1)$ \\
\hline $\begin{array}{l}\text { Sepsis other than neutropenic } \\
\text { complications }\end{array}$ & $133(17.6)$ \\
\hline Intercurrent disease & $15(2.0)$ \\
\hline $\begin{array}{l}\text { Cardiopulmonary arrest of unknown } \\
\text { cause }\end{array}$ & $8(1.1)$ \\
\hline
\end{tabular}
status.

cell tumors, urinary bladder cancer, uterine corpus cancer, malignant thymoma, melanoma, mesothelioma, adrenocortical carcinoma, hemangiopericytoma, neuroendocrine carcinoma, malignant phaeochromocytoma, gastrointestinal stromal tumors and unknown primary sites. A total of 587 (77.9\%) patients passed away eventually due to their underlying malignancies. One hundred and fifty-nine $(21.1 \%)$ patients died of non-malignancy related causes including neutropenic fever/sepsis (8 patients, 1.1\%), sepsis other than neutropenic complications (133 patients, $17.6 \%$ ), and intercurrent diseases (15 patients, 2.0\%). Another 8 (1.1\%) patients died of sudden cardiopulmonary arrest of unknown cause.

\section{Survival outcomes}

Figure $1 A, B$ showed the Kaplan-Meier curves for overall 

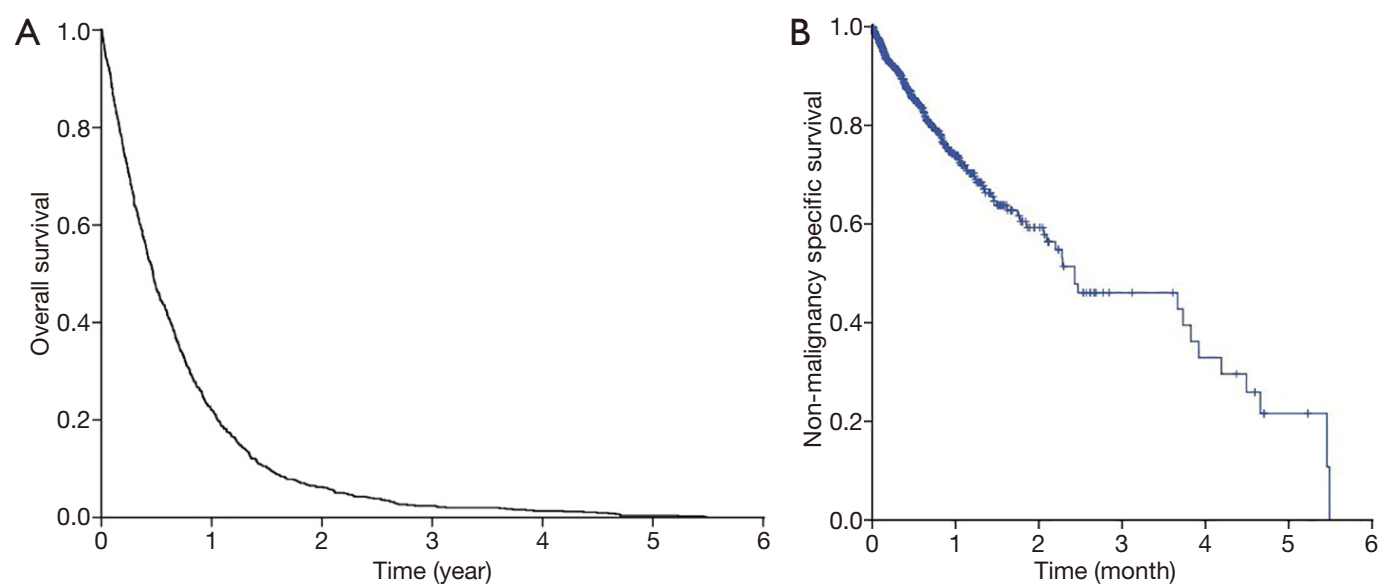

Figure 1 Kaplan-Meier curves showing (A) overall survival and (B) non-malignancy specific survival in the whole study population (N=754).
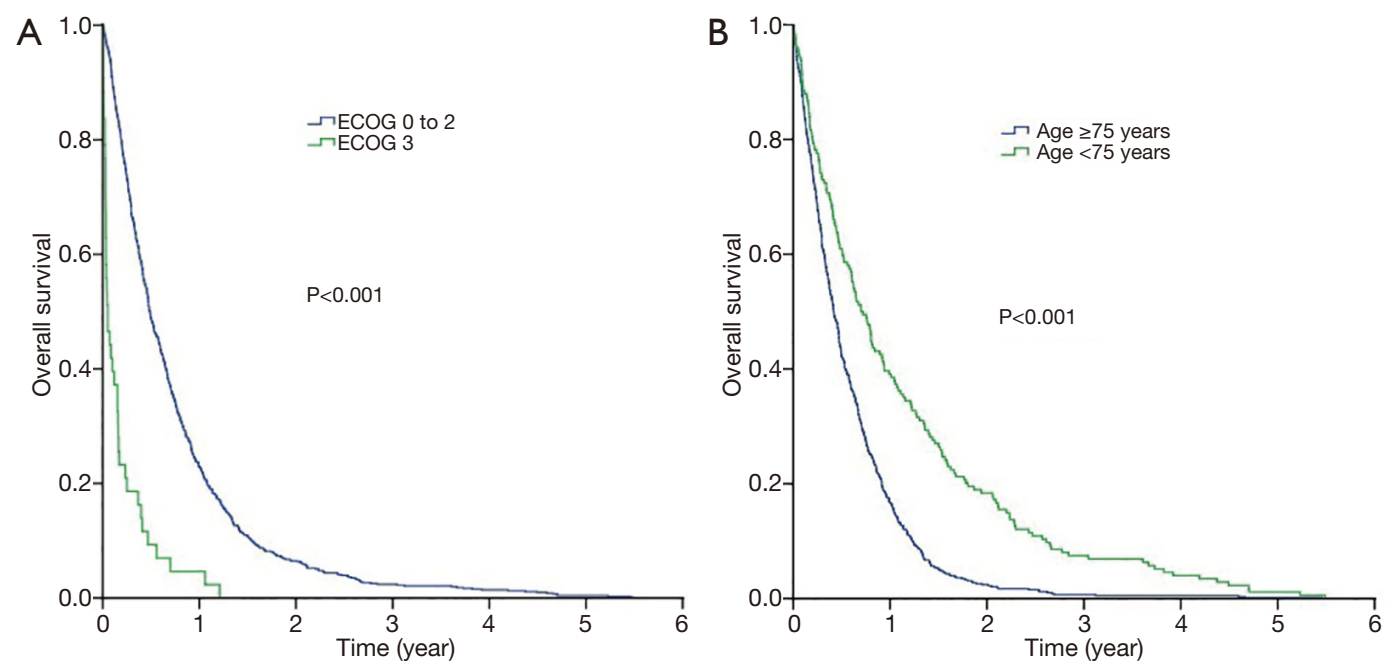

Figure 2 Kaplan-Meier curves showing (A) overall survival in the whole study population stratified by Eastern Cooperative Oncology Group (ECOG) performance status (PS) 0-2 versus 3 and (B) overall survival in the whole study population stratified by age 75 years versus age $<75$ years $(\mathrm{N}=754)$.

survival and non-malignancy specific survival for all patients in our study $(\mathrm{N}=754)$. The median overall survival for the whole cohort was 5.6 months [95\% confidence interval (CI), 5.1-6.1 months] while the median non-malignancy specific survival was 5.5 months (95\% CI, 4.3-6.8 months). Logrank tests revealed that those who had a worse ECOG PS 3 enjoyed shorter median overall survival compared to those who had better ECOG PS [0-2] (1.4 vs. 5.8 months; $\mathrm{P}<0.001)$ (Figure $2 A$ ). Similarly, those who aged 75 years survived shorter compared to those who were younger [median overall survival 5.0 months (95\% CI, 4.5-5.5 months) vs. 8.4 months (95\% CI, 6.7-10.1 months); $\mathrm{P}<0.001]$ (Figure 2B).
With respect to non-malignancy specific survival, patients who had worse ECOG PS 3 had a shorter median non-malignancy specific survival (1.2 months, $95 \%$ CI, 0.0-2.9 months) compared to those who had better ECOG PS 0-2 (5.7 months, 95\% CI, 4.1-7.2 months; $\mathrm{P}<0.001)$ (Figure $3 A$ ). Likewise, the non-malignancy specific survival of patients with age 75 years ( 4.5 months; $95 \%$ CI, 3.25.8 months) was shorter than those who were younger (6.2 months; 95\% CI, 3.5-9.0 months, $\mathrm{P}=0.005$ ) (Figure 3B).

Table 3 displayed the baseline patient characteristics stratified according to the days to death (within 42 days or longer than 42 days) after the start of last line of palliative 

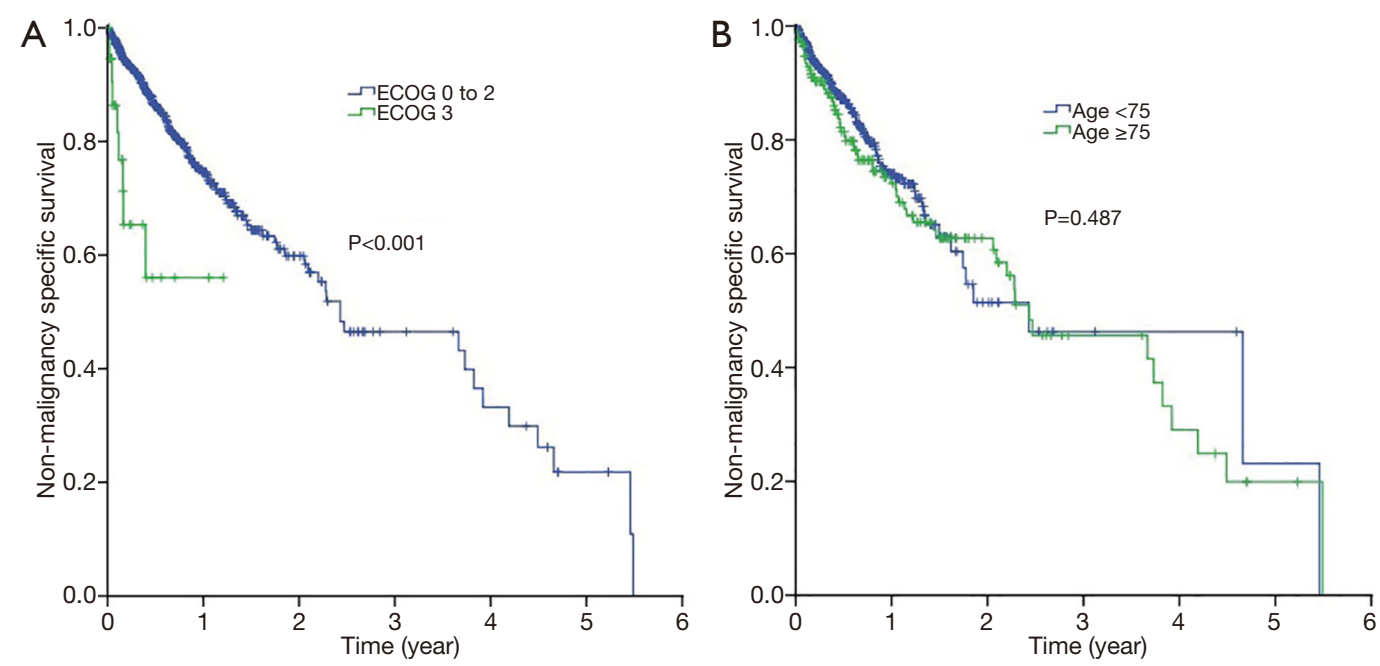

Figure 3 Kaplan-Meier curves showing (A) non-malignancy specific survival in the whole study population stratified by Eastern Cooperative Oncology Group (ECOG) performance status (PS) 0-2 versus 3 and (B) non-malignancy specific survival in the whole study population stratified by age 75 years versus age $<75$ years.

systemic treatment. In general, patients who died within 42 days of start of last line of palliative systemic treatment was worse in their ECOG PS $(\mathrm{P}<0.001)$, has a higher incidence of active brain metastasis $(\mathrm{P}=0.027)$ and liver metastasis $(\mathrm{P}=0.016)$, received more prior lines of palliative systemic treatment $(\mathrm{P}<0.001)$, has higher white cell counts $(\mathrm{P}<0.001)$, higher absolute neutrophil counts $(\mathrm{P}<0.001)$, and lower serum albumin $(\mathrm{P}<0.001)$. In addition, more non-malignancy related deaths were observed in those who died within 42 days after the start of last line of palliative systemic treatment $(\mathrm{P}=0.003)$.

\section{Identification of predictive factors for non-malignancy- related death by univariable and multivariable analyses}

Table 4 showed the results of univariable and multivariable analyses for all non-malignancy related deaths $(\mathrm{n}=159)$. In univariable analysis, it was found that age 75 years $(\mathrm{P}<0.001)$, male gender $(\mathrm{P}=0.008)$, active liver metastasis $(\mathrm{P}=0.002)$ and chemotherapy or chemotherapy plus targeted therapy as last line of palliative systemic treatment $(\mathrm{P}=0.001)$ were predictive factors for non-malignancy specific survival. In multivariable analysis, age 75 years $(\mathrm{P}<0.001)$, male gender $(\mathrm{P}=0.012)$ and active liver metastasis $(\mathrm{P}=0.015)$ were significant predictive factors for non-malignancy specific survival, indicating that advanced age, male patients and presence of active liver metastasis increased the risk of nonmalignancy related death.

\section{Identification of predictive factors for non-malignancy specific survival within 42 days since the start of last line of palliative systemic treatment by univariable and multivariable analyses}

The predictive factors for non-malignancy specific survival within 42 days since the start of last line of palliative systemic treatment were evaluated by Cox proportional hazard models with univariable and multivariable analyses (Table 5). Univariable analysis revealed that age 75 years $(\mathrm{P}=0.005)$, and active liver metastasis $(\mathrm{P}=0.050)$ were significant predictive factors; while male gender and serum haemoglobin within 1 week before the last line of palliative systemic treatment were borderline significant.

In multivariable analysis, only age 75 years $(\mathrm{P}=0.007)$ and active liver metastasis $(\mathrm{P}=0.042)$ were significant predictive factors. In other words, patients who were 75 years old and those who had active liver metastasis had a 2.012 and 1.115 times higher chance respectively to die of nonmalignant causes within 42 days since the start of last line of palliative systemic treatment.

\section{Discussion}

We know that it is difficult to accurately predict survival of individual metastatic cancer patients. However, most of the time, one of the bases for deciding who should be given palliative systemic therapy is our survival prediction. 
Table 3 Baseline patient characteristics stratified according to the days to death (within 42 days versus longer than 42 days) after last line of palliative systemic treatment $(\mathrm{N}=754)$

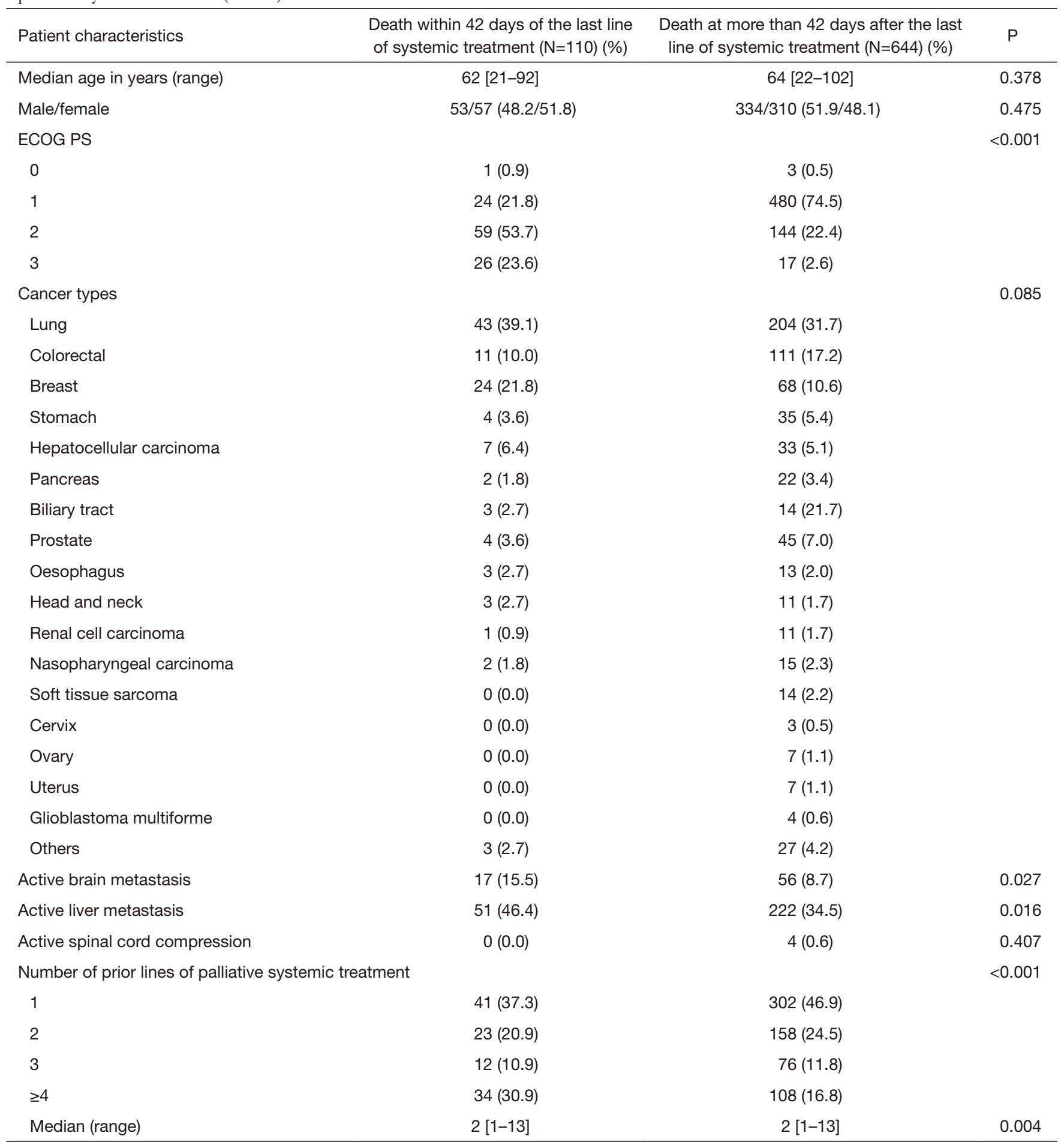

Table 3 (continued) 
Table 3 (continued)

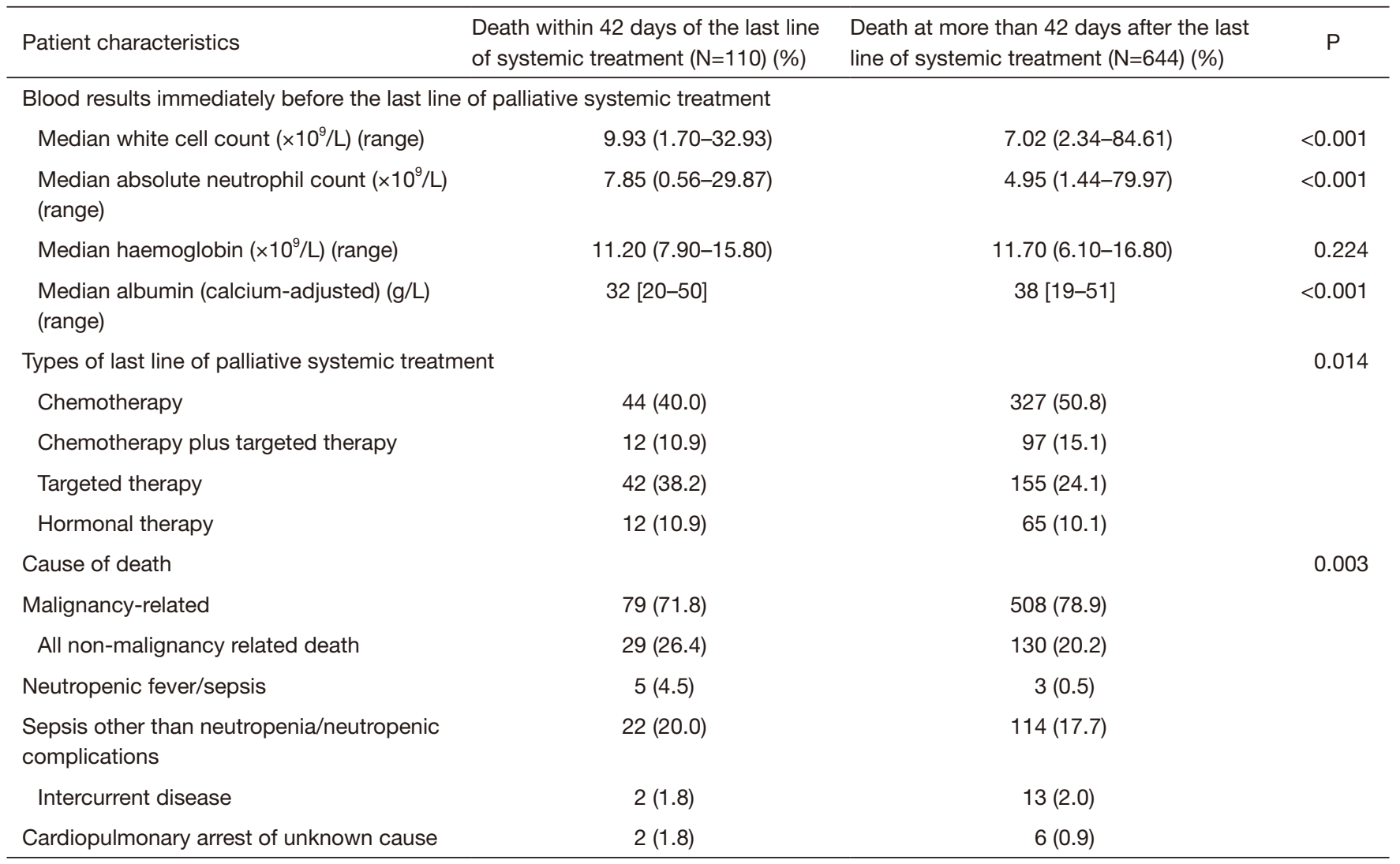

ECOG, Eastern Cooperative Oncology Group; PS, performance status.

Table 4 Univariable and multivariable analyses for non-malignancy related death $(\mathrm{n}=159)$

\begin{tabular}{|c|c|c|c|c|c|c|}
\hline \multirow{2}{*}{ Patient characteristics } & \multicolumn{3}{|c|}{ Univariable analysis } & \multicolumn{3}{|c|}{ Multivariable analysis } \\
\hline & $\mathrm{RR}$ & $95 \% \mathrm{Cl}$ & $\mathrm{P}$ & $\mathrm{RR}$ & $95 \% \mathrm{Cl}$ & $\mathrm{P}$ \\
\hline Age $\geq 75$ years & 0.389 & $0.266-0.570$ & $<0.001$ & 0.363 & $0.254-0.573$ & $<0.001$ \\
\hline ECOG PS $\geq 3$ & 0.993 & $0.465-2.120$ & 0.985 & ND & & \\
\hline Active brain metastasis & 1.157 & $0.628-2.132$ & 0.639 & ND & & \\
\hline Active spinal cord compression & 0.268 & $0.038-1.920$ & 0.190 & ND & & \\
\hline Number of prior lines of palliative systemic treatment & 0.948 & $0.860-1.045$ & 0.285 & ND & & \\
\hline Median white cell count & 1.002 & $0.969-1.037$ & 0.889 & ND & & \\
\hline Median absolute neutrophil count & 1.004 & $0.969-1.041$ & 0.821 & ND & & \\
\hline
\end{tabular}


Table 5 Univariable and multivariable analyses for non-malignancy-related death within 42 days after the last line of palliative systemic treatment $(\mathrm{n}=110)$

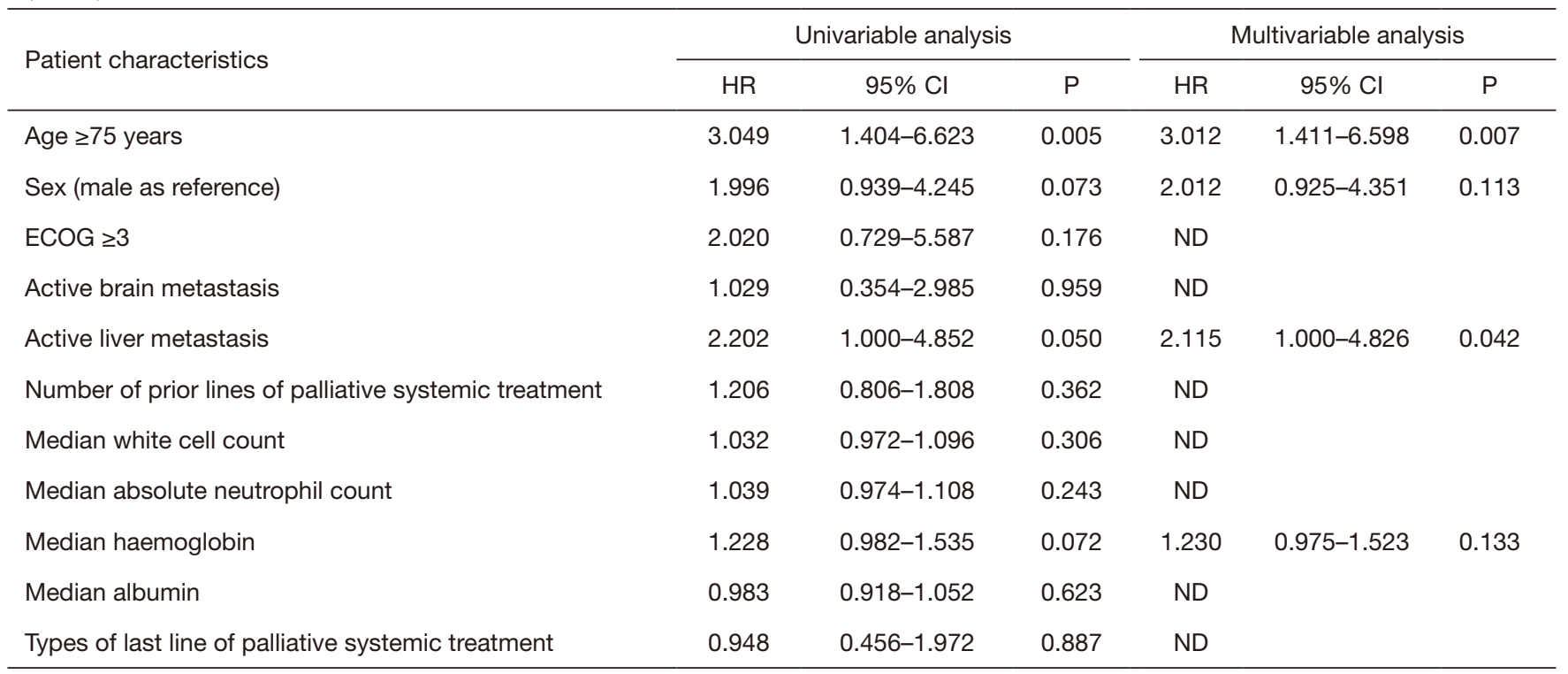

Only variables found significant in univariable analysis $(\mathrm{P}<0.1)$ will be considered in subsequent multivariable analysis. $\mathrm{Cl}$, confidence interval; ECOG, Eastern Cooperative Oncology Group; HR, hazard ratio; PS, performance status; ND, not done.

It is always a great challenge to identify and determine who will benefit most and gain the most survival benefit from systemic therapy. At the same time, we should not forget that some patients cannot enjoy the benefit, suffer from treatment toxicity, and may even complicate with death.

To the best of our knowledge, our study is the largest investigating the factors correlating with shorter nonmalignancy related survival after the start of last line of palliative systemic treatment. Our study highlighted the importance of patient selection for palliative systemic treatment. We found that a significant proportion of patients who were predicted by their oncologist to have at least 3 months of survival, and subsequently received palliative systemic treatment, actually lived less than half of that. Patients who died within 6 weeks since the start of their last line of palliative systemic treatment had a higher percentage of worse ECOG PS 3, active brain metastasis, active liver metastasis and lower serum albumin, and were previously treated with more lines of palliative systemic treatment $(30.9 \%$ had received $\geq 4$ lines as compared to $16.8 \%$ of patients who survived $>6$ weeks). This suggested that in general they were poor performers with limited physique and suboptimal body reserve as compared to those who survived for more than 6 weeks after starting the last line of palliative systemic treatment. In addition, they tended to have a higher white cell count and absolute neutrophil count. We postulated that they might have occult subclinical signs of infection, but imbalanced distribution between the two subgroups in our retrospective study cannot be totally excluded.

Amongst patients with a $\leq 6$ weeks survival who succumbed to conditions other than their own malignancies, those who were 75 years old and those with liver metastasis were most at risk. Their shorter-than-expected survival is not related to the disease itself, and could have been related to the treatment given.

With our study results, we remind that oncologists should be aware and be extra-cautious when encountering elderly ( 75 years old) cancer patients with liver metastasis, especially with regard to the issue of starting palliative systemic therapy. On the other hand, we also acknowledge that there are many other reasons leading to decision of starting palliative systemic treatment. Not infrequently do we encounter patients and/or relatives who were demanding active systemic therapy despite the patient being obviously dying within a few days. There may be complicated cultural and emotional issues behind such requests, and sometimes it is very difficult for us to refuse all of them. Sometimes relatives were feeling guilty of not caring enough for the patient in the past. Sometimes they were in desperate need of hope. Sometimes patients may have been started on systemic treatment by other 
oncologists elsewhere, and then insisted to continue the treatment in our university-affiliated center, despite our opinion of not starting the treatment at all in the first place. Regardless, we advocate that this particular group of elderly malignant patients with liver metastasis should have early multidisciplinary palliative care service provided and integrated into their care. Palliative service provision has been shown to reduce the aggressiveness of end of life care in terminal cancer patients, including less likely to receive chemotherapy during the last month of life, less likely to receive cardiopulmonary resuscitation or mechanical ventilation, less likely to die in intensive care unit, and also can lead to a reduced health care cost (61-63). We believe that with early integration of multidisciplinary palliative care into cancer patient management, more patients can be spared the unnecessary toxicity of futile systemic treatment, and the quality of care of terminal cancer patients can be significantly improved.

In our study, ECOG PS $\geq 3$ was found not a significant predictive factor for non-malignancy related death per se, only borderline significant in univariable analysis $(\mathrm{P}=0.176)$ and non-significant in multivariable analysis for early non-malignancy related death within 42 days of last line of systemic treatment. This may be related in part to the fact that poor PS itself is a poor predictive factor for both malignancy-related and non-malignancy related mortality already, as clearly shown by its effect on the overall survival of the whole study population (Figure $2 A$ ). And as expected, it is significantly related to a shorter survival of $\leq 42$ days in the whole study population (Table 3). On the other hand, our data relied heavily on the accuracy of the electronic patient records. Some data such as ECOG PS were not explicitly stated in the notes entered into the system by the oncologist during consultation, and had to be deduced from other peripheral description during the data-input process. This has introduced some uncertainty in the accuracy of the data with regard to ECOG PS, and may have also contributed to this finding.

In this study, there is no predictive entity found in routine hematology and biochemistry checks that can significantly predict shorter non-malignancy related survival. Speculation of other biochemistry such as markers of acute phase response (APR) like C-reactive protein (CRP) or erythrocyte sedimentation rate (ESR) may be related to non-malignancy related deaths have arisen. However, due to the retrospective nature of this study, and as these APR markers were not routinely checked in cancer patients, the speculation cannot be put to test here.
There are several limitations in this study. The retrospective nature leading to imbalance of distribution of some baseline characteristics in different patient subgroups was one limitation. However, a relatively large number of patients have been included in this study so these results should be reasonably representative and acceptable. This is also a very heterogeneous group of patients, with a wide variety of primary cancers. Different cancers have different natural history and illness trajectory after metastasizing, which may have affected treatment decisions. The study can be repeated on a patient population with a single cancer diagnosis to alleviate this confounding factor.

We understand that cancer patients are predisposed to sepsis or other life-threatening complications. It may be argued that it is difficult to differentiate between malignancy-related and non-malignancy related mortality, and the differentiation may be too arbitrary. In this study, we have tried our best to define malignancy-related deaths as those resulting from multi-organ failure, and sepsis as those who truly died with clinical \& biochemical evidence such as fever and increased white blood cell counts. We believe that the relationship between patient's systemic treatment and their sepsis event cannot be disproved, and that the systemic treatment could have 'hastened' the sepsis event. In light of this, we believe that our definition and results are reliable.

Future prospective studies are needed to verify our study findings, and probably should be done in only one cancer entity to remove the confounding factor. The issue of quality of life change in this group of patients is also worth studying. Recently published data suggested a significant association between chemotherapy use and worse quality of life amongst those with a good baseline ECOG PS 1, highlighting the potential harm of chemotherapy in these patients (59). It will be interesting to see if this phenomenon applies to our basically Asian Chinese population.

With the exponentially growing use of targeted therapy and immunotherapy in multiple cancer entities, the effect of targeted therapy and/ or immunotherapy as opposed to chemotherapy in terminal cancer population is worth looking into. So far, most data in this population were looking into chemotherapy alone as treatment, without any looking into the effect of targeted therapy and/or immunotherapy in this population. New drugs are costly, and contribute much to the rising cost of therapy worldwide (64). Cost effectiveness of such interventions should also be carefully evaluated, especially in the QOL aspect in this population with a limited expected survival. 


\section{Conclusions}

From this study, we were able to demonstrate that those patients with advanced age ( 75 years) and those who had active liver metastasis suffered from a higher risk of early non-malignancy related death after palliative systemic treatment for their metastatic malignancies, with their actual survival shortened by half or more from the expected. This has shed a light for both the oncologists and the patients when it comes to the decision-making process of proceeding with further palliative systemic chemotherapy or not. In real-world clinical setting, it is always a great challenge to maintain equipoise between survival prolongation and treatment-related toxicities or even death. It will be easier to reach a consensus between health care professionals and the patients as well as their relatives in the decision-making process if there are known predictive factors correlating with unwanted non-malignancy related mortality.

\section{Acknowledgments}

Funding: None.

\section{Footnote}

Provenance and Peer Review: This article was commissioned by the Guest Editors (Rebecca Yeung and Tai Chung Lam) for the series "Integrating Palliative Medicine in Oncology Care: The Hong Kong Experience", published in Annals of Palliative Medicine. The series "Integrating Palliative Medicine in Oncology Care: The Hong Kong Experience" was commissioned by the editorial office without any funding or sponsorship. The authors have no other conflicts of interest to declare.

Conflicts of Interest: Both authors have completed the ICMJE uniform disclosure form (available at http://dx.doi. org/10.21037/apm.2019.09.06). The authors have no other conflicts of interest to declare.

Ethical Statement: The authors are accountable for all aspects of the work in ensuring that questions related to the accuracy or integrity of any part of the work are appropriately investigated and resolved. The study was conducted in accordance with the Declaration of Helsinki (as revised in 2013). Since our study was based on retrospective data retrieval, and no clinical intervention was done, IRB approval has been waived.
Open Access Statement: This is an Open Access article distributed in accordance with the Creative Commons Attribution-NonCommercial-NoDerivs 4.0 International License (CC BY-NC-ND 4.0), which permits the noncommercial replication and distribution of the article with the strict proviso that no changes or edits are made and the original work is properly cited (including links to both the formal publication through the relevant DOI and the license). See: https://creativecommons.org/licenses/by-nc-nd/4.0/.

\section{References}

1. Mok TS, Wu YL, Thongprasert S, et al. Gefitinib or carboplatin-paclitaxel in pulmonary adenocarcinoma. $\mathrm{N}$ Engl J Med 2009;361:947-57.

2. Fukuoka M, Wu YL, Thongprasert S, et al. Biomarker Analyses and Final Overall Survival Results From aPhase III, Randomized, Open-Label, First-Line Study of Gefitinib Versus Carboplatin/Paclitaxel in Clinically Selected Patients With Advanced Non-Small-Cell Lung Cancer in Asia (IPASS). J Clin Oncol 2011;29:2866-74.

3. Maemondo M, Inoue A, Kobayashi K, et al. Gefitinib or chemotherapy for non-small cell lung cancer with mutated EGFR. N Engl J Med 2010;362:2380-8.

4. Mitsudomi T, Morita S, Yatabe Y, et al. Gefitinib versus cisplatin plus docetaxel in patients with non-small lung cancer harboring mutations of the epidermal growth factor receptor (WJTOG3405): An open label, randomized phase 3 trial. Lancet Oncol 2010;11:121-8.

5. Han JY, Park K, Kim SW, et al. First-SIGNAL: First-line single-agent iressa versus gemcitabine and cisplatin trial in never-smokers with adenocarcinoma of the lung. J Clin Oncol 2012;30:1122-8.

6. Zhou C, Wu YL, Chen G, et al. Erlotinib versus chemotherapy as first-line treatment for patients with advanced EGFR mutation-positive non-small cell lung cancer (OPTIMAL, CTONG-0802): A multicenter, open-label, randomized, phase 3 study. Lancet Oncol 2011;12:735-42.

7. Rosell R, Carcereny E, Gervais R, et al. Erlotinib versus standard chemotherapy as first-line treatment for European patients with advanced EGFR mutation-positive non-small-cell lung cancer (EURTAC): a multicenter, open-label, randomized phase 3 trial. Lancet Oncol 2012;13:239-46.

8. Sequist LV, Yang JC, Yamamoto N, et al. Phase III study of afatinib or cisplatin plus pemetrexed in patients with metastatic lung adenocarcinoma with EGFR mutations. J 
Clin Oncol 2013;31:3327-34.

9. $\mathrm{Wu} \mathrm{YL}$, Zhou C, Hu CP, et al. Afatinib versus cisplatin plus gemcitabine for first-line treatment of Asian patients with advanced non-small-cell lung cancer harbouring EGFR mutations (LUX-Lung 6): an open-label, randomised phase 3 trial. Lancet Oncol 2014;15:213-22.

10. Solomon BJ, Mok T, Kim DW, et al. First-line crizotinib versus chemotherapy in ALK-positive lung cancer. N Engl J Med 2014;371:2167-77.

11. Shaw AT, Kim DW, Mehra R, et al. Ceritinib in ALKrearranged non-small-cell lung cancer. $\mathrm{N}$ Engl J Med 2014;370:1189-97.

12. Scagliotti GV, Parikh P, von Pawel J, et al. Phase III Study Comparing Cisplatin Plus Gemcitabine With Cisplatin Plus Pemetrexed in Chemotherapy-Naive Patients With Advanced-Stage Non-Small-Cell Lung Cancer. J Clin Oncol 2008;26:3543-51.

13. Barlesi F, Scherpereel A, Rittmeyer A, et al. Randomized phase III trial of maintenance bevacizumab with or without pemetrexed after first-line induction with bevacizumab, cisplatin, and pemetrexed in advanced nonsquamous nonsmall-cell lung cancer: AVAPERL (MO22089). J Clin Oncol 2013;31:3004-11.

14. Hurwitz H, Fehrenbacher L, Novotny W, et al. Bevacizumab plus irinotecan, fluorouracil, and leucovorin for metastatic colorectal cancer. $\mathrm{N}$ Engl J Med 2004;350:2335-42.

15. Van Cutsem E, Köhne CH, Hitre E, et al. Cetuximab and chemotherapy as initial treatment for metastatic colorectal cancer. N Engl J Med 2009;360:1408-17.

16. Maughan TS, Adams RA, Smith CG, et al. Addition of cetuximab to oxaliplatin-based first-line combination chemotherapy for treatment of advanced colorectal cancer: results of the randomised phase 3 MRC COIN trial. Lancet 2011;377:2103-14.

17. Tol J, Koopman M, Cats A, et al. Chemotherapy, bevacizumab, and cetuximab in metastatic colorectal cancer. N Engl J Med 2009;360:563-72.

18. Loupakis F, Cremolini C, Masi G, et al. Initial therapy with FOLFOXIRI and bevacizumab for metastatic colorectal cancer. N Engl J Med 2014;371:1609-18.

19. Slamon DJ, Leyland-Jones B, Shak S, et al. Use of chemotherapy plus a monoclonal antibody against HER2 For metastatic breast cancer that overexpresses HER2. N Engl J Med 2001;344:783-92.

20. Valero V, Forbes J, Pegram MD, et al. Multicenter phase III randomized trial comparing docetaxel and trastuzumab with docetaxel, carboplatin, and trastuzumab as first-line chemotherapy for patients with HER2-gene-amplified metastatic breast cancer (BCIRG 007 study): two highly active therapeutic regimens. J Clin Oncol 2011;29:149-56.

21. Baselga J, Cortés J, Kim SB, et al. Pertuzumab plus trastuzumab plus docetaxel for metastatic breast cancer. $\mathrm{N}$ Engl J Med 2012;366:109-19.

22. Swain SM, Baselga J, Kim SB, et al. CLEOPATRA Study Group. Pertuzumab, trastuzumab, and docetaxel in HER2-positive metastatic breast cancer.N Engl J Med 2015;372:724-34.

23. Swain SM, Kim SB, Cortés J, et al. Pertuzumab, trastuzumab, and docetaxel for HER2-positive metastatic breast cancer (CLEOPATRA study): overall survival results from a randomised, double-blind, placebo-controlled, phase 3 study. Lancet Oncol 2013;14:461-71.

24. Baselga J, Campone M, Piccart M, et al. Everolimus in postmenopausal hormone-receptor-positive advanced breast cancer.N Engl J Med 2012;366:520-9.

25. Bang YJ, Van Cutsem E, Feyereislova A, et al. Trastuzumab in combination with chemotherapy versus chemotherapy alone for treatment of HER2-positive advanced gastric or gastro-oesophageal junction cancer (ToGA): a phase 3, open-label, randomised controlled trial. Lancet 2010;376:687-97.

26. Von Hoff DD, Ervin T, Arena FP, et al. Increased survival in pancreatic cancer with nab-paclitaxel plus gemcitabine. N Engl J Med 2013;369:1691-703.

27. Conroy T, Desseigne F, Ychou M, et al. Groupe Tumeurs Digestives of Unicancer; PRODIGE Intergroup. FOLFIRINOX versus gemcitabine for metastatic pancreatic cancer. N Engl J Med 2011;364:1817-25.

28. Vermorken JB, Mesia R, Rivera F, et al. Platinum-based chemotherapy plus cetuximab in head and neck cancer. $\mathrm{N}$ Engl J Med 2008;359:1116-27.

29. Ryan CJ, Smith MR, de Bono JS, et al. Abiraterone in metastatic prostate cancer without previous chemotherapy. N Engl J Med 2013;368:138-48.

30. Sweeney CJ, Chen YH, Carducci M, et al. Chemohormonal Therapy in Metastatic HormoneSensitive Prostate Cancer. N Engl J Med 2015;373:737-46.

31. Gilbert MR, Dignam JJ, Armstrong TS, et al. A randomized trial of bevacizumab for newly diagnosed glioblastoma. N Engl J Med 2014;370:699-708.

32. Llovet JM, Ricci S, Mazzaferro V, et al. Sorafenib in advanced hepatocellular carcinoma. N Engl J Med 2008;359:378-90.

33. Cheng AL, Kang YK, Chen Z, et al. Efficacy andsafety 
of sorafenib in patients in the Asia-Pacific regionwith advanced hepatocellular carcinoma: A phase III randomised, double-blind, placebo-controlled trial. Lancet Oncol 2009; 10:25-34.

34. Robert C, Thomas L, Bondarenko I, et al. Ipilimumab plus dacarbazine for previously untreated metastatic melanoma. N Engl J Med 2011;364:2517-26.

35. Chapman PB, Hauschild A, Robert C, et al. Improved survival with vemurafenib in melanoma with BRAF V600E mutation. N Engl J Med 2011;364:2507-16.

36. Flaherty KT, Robert C, Hersey P, et al. Improved survival with MEK inhibitionin BRAF-mutated melanoma. N Engl J Med 2012;367:107-14.

37. Larkin J, Ascierto PA, Dréno B, et al. Combined vemurafenib and cobimetinib in BRAF-mutated melanoma. N Engl J Med 2014;371:1867-76.

38. Long GV, Stroyakovskiy D, Gogas H, et al. Combined BRAF and MEK inhibition versus BRAF inhibition alone in melanoma. N Engl J Med 2014;371:1877-88.

39. Robert C, Karaszewska B, Schachter J, et al. Improved overall survival in melanoma with combined dabrafenib and trametinib. N Engl J Med 2015;372:30-9.

40. Larkin J, Chiarion-Sileni V, Gonzalez R, et al. Combined nivolumab and ipilimumabor monotherapy in untreated melanoma. N Engl J Med 2015;373:23-34.

41. Escudier B, Pluzanska A, Koralewski P, et al. Bevacizumab plus interferon alfa-2a for treatment of metastatic renal cell carcinoma: a randomised, double-blind phase III trial. Lancet 2007;370:2103-11.

42. Escudier B, Eisen T, Stadler WM, et al. Sorafenib in advanced clear-cell renal-cell carcinoma. N Engl J Med 2007;356:125-34.

43. Motzer RJ, Hutson TE, Tomczak P, et al. Sunitinib versus interferon-alfa in metastatic renal-cell carcinoma. N Engl J Med 2007;356:115-24.

44. Motzer RJ, Thomas E, Hutson TE, et al. Overall survival and updated results for sunitinib compared with interferon alfa in patients with metastatic renal cell carcinoma. J Clin Oncol 2009;27:3584-90.

45. Hudes G, Carducci M, Tomczak P, et al. Temsirolimus, interferon alfa,or both for advanced renal-cell carcinoma. N Engl J Med 2007;356:2271-81.

46. Motzer RJ, Hutson TE, David Cella D, et al. Pazopanib versus sunitinib in metastatic renal-cell carcinoma. N Engl J Med 2013;369:722-31.

47. Tewari KS, Sill MW, Long III HJ, et al. Improved survival with bevacizumab in advanced cervical cancer. $\mathrm{N}$ Engl J Med 2014;370:734-43.
48. Perren TJ, Swart AM, Pfisterer J, et al. A phase 3 trial of bevacizumab in ovarian cancer. N Engl J Med 2011;365:2484-96.

49. Burger RA, Brady MF, Bookman MA, et al. Gynecologic Oncology Group. Incorporation of bevacizumab in the primary treatment of ovarian cancer. N Engl J Med 2011;365:2473-83.

50. Brose MS, Nutting CM, Jarzab B, et al. Sorafenib in radioactive iodine-refractory, locally advanced or metastatic differentiated thyroid cancer: a randomised, double-blind, phase 3 trial. Lancet 2014;384:319-28.

51. Schlumberger M, Tahara M, Wirth LJ, et al. Lenvatinib versus placebo in radioiodine-refractory thyroid cancer. $\mathrm{N}$ Engl J Med 2015;372:621-30.

52. Näppä U, Lindqvist O, Rasmussen BH, Axelsson B. Palliative chemotherapy during the last month of life. Ann Oncol 2011;22:2375-80.

53. Emanuel EJ, Young-Xu Y, Levinsky NG et al. Chemotherapy use among Medicare beneficiaries at the end of life. Ann Intern Med 2003;138:639-43.

54. Earle CC, Neville BA, Landrum MB et al. Trends in the aggressiveness of cancer care near the end of life. J Clin Oncol 2004;22:315-21.

55. Andreis F, Rizzi A, Rota L, et al. Chemotherapy use at the end of life. A retrospective single centre experience analysis. Tumori 2011;97:30-4.

56. Matsuyama R, Reddy S, Smith TJ. Why do patients choose chemotherapy near the end of life? A review of the perspective of those facing death from cancer. J Clin Oncol 2006;24:3490-6.

57. Keam B, Oh DY, Lee SH et al. Aggressiveness of cancercare near the end-of-life in Korea. Jpn J Clin Oncol 2008;38:381-6.

58. Schnipper LE, Smith TJ, Raghavan D, et al. American Society of Clinical Oncology identifies five key opportunities to improve care and reduce costs: the top five list for oncology. J Clin Oncol 2012;30:1715-24.

59. Prigerson HG, Bao Y, Shah MA, et al. Chemotherapy use, performance status, and quality of life at the end of life. JAMA Oncol 2015;1:778-84.

60. Glare P, Virik K, Jones $M$ et al. A systemic review of physicians' survival predictions in terminally ill cancer patients. BMJ 2003;327:195-8.

61. Luta X, Maessen M, Egger M, et al. Measuring intensity of end of life care. PLoS One. 2015;10:e0123764.

62. Karim SM, Zekri J, Abdelghany E, et al. Time from last chemotherapy to death and its correlation with end of life care in a referral hospital. Indian J Med Paediatr Oncol 
2015;36:55-9.

63. Chiang JK, Kao YH. The impact of hospice care on survival and cost saving among patients with liver cancer: a national longitudinal population-based study in Taiwan.
Support Care Cancer 2015;23:1049-55.

64. Aggarwal S. Targeted cancer therapies. Nat Rev Drug Discov 2010;9:427-8.

Cite this article as: Ho PY, Lee HF. Factors correlating with shorter survival after treatment: aiding oncologists to choose who (not) to receive palliative systemic therapy. Ann Palliat Med 2020;9(6):4430-4445. doi: 10.21037/apm.2019.09.06 